Communication

\title{
Degradation Resistance and In Vitro Cytocompatibility of Iron-Containing Coatings Developed on WE43 Magnesium Alloy by Micro-Arc Oxidation
}

\author{
Rongfa Zhang ${ }^{1, * \mathbb{D}}$, Zeyu Zhang ${ }^{1}$, Yuanyuan Zhu ${ }^{1,2}{ }^{,}$Rongfang Zhao ${ }^{1}$, Shufang Zhang ${ }^{1}$, \\ Xiaoting Shi ${ }^{1}$, Guoqiang Li ${ }^{1}$, Zhiyong Chen ${ }^{1}$ and Ying Zhao ${ }^{2, *}$ \\ 1 School of Materials and Electromechanics, Jiangxi Science and Technology Normal University, \\ Nanchang 330013, China; 18271690030@163.com (Z.Z.); Yuanyuanzhu_01@163.com (Y.Z.); \\ zhaorfamy@126.com (R.Z.); zhang63793@163.com (S.Z.); shixiaoting1001@163.com (X.S.); \\ 18435163505@126.com (G.L.); yong872018744@163.com (Z.C.) \\ 2 Shenzhen Institutes of Advanced Technology, Chinese Academy of Sciences, Shenzhen 518055, China \\ * Correspondence: rfzhang-10@163.com (R.Z.); ying.zhao@siat.ac.cn (Y.Z.); Tel./Fax: +86-791-8853-7923 (R.Z.); \\ Tel.: +86-755-8658-5229 (Y.Z.); Fax: +86-755-8658-5222 (Y.Z.)
}

Received: 6 October 2020; Accepted: 18 November 2020; Published: 23 November 2020

\begin{abstract}
Iron (Fe) is an important trace element for life and plays vital functions in maintaining human health. In order to simultaneously endow magnesium alloy with good degradation resistance, improved cytocompatibility, and the proper Fe amount for the body accompanied with degradation of $\mathrm{Mg}$ alloy, Fe-containing ceramic coatings were fabricated on WE43 Mg alloy by micro-arc oxidation (MAO) in a nearly neutral $\mathrm{pH}$ solution with added $0,6,12$, and $18 \mathrm{~g} / \mathrm{L}$ ferric sodium ethylenediaminetetraacetate $(\mathrm{NaFeY})$. The results show that compared with the bare $\mathrm{Mg}$ alloy, the MAO samples with developed Fe-containing ceramic coatings significantly improve the degradation resistance and in vitro cytocompatibility. Fe in anodic coatings is mainly present as $\mathrm{Fe}_{2} \mathrm{O}_{3}$. The increased $\mathrm{NaFeY}$ concentration favorably contributes to the enhancement of Fe content but is harmful to the degradation resistance of MAO coatings. Our study reveals that the developed Fe-containing MAO coating on Mg alloy exhibits potential in clinical applications.
\end{abstract}

Keywords: magnesium alloy; micro-arc oxidation; iron; degradation resistance; cytocompatibility

\section{Introduction}

Due to the similar specific density and Young's modulus to natural bone, and many $\mathrm{Mg}$ ion-associated biological functions in vivo, magnesium alloy is believed to be excellent for biodegradable metallic implants [1-3]. However, too rapid degradation in bilogical environments restricts its clinical applications [1,2]. In fact, the degradation resistance of $\mathrm{Mg}$ alloy can be improved by using alloying, surface treatment, or mechanical processing [1,2].

Micro-arc oxidation (MAO), also known as plasma electrolytic oxidation, is an innovative surface treatment method for $\mathrm{Mg}$ alloy and titanium alloy [1,4-6]. MAO treatment not only significantly improves the degradation resistance and wear resistance of $\mathrm{Mg}$ alloy, but also produces multiple biofunctional ceramic coatings [3]. The properties of MAO coatings are determined by several factors including substrate materials [7] and electrolyte composition and concentration, as well as electrical parameters [3]. Due to the long-term temperature stability, very good mechanical property, and low toxicity of rare earth elements, WE43 alloys are widely used as biomedical Mg alloys [1,8]. During MAO, the electrolyte composition and concentration significantly determine coating properties by affecting 
the coating chemical composition, phase structure, and surface characteristics (morphology, pore size, and thickness) [1,9]. Besides substrate materials and electrolytes, electrical parameters including frequency, duty cycle, current density, and treatment time are also closely correlated with the coating property [10].

Besides $\mathrm{Mg}$ alloy, zinc and iron meet the requirements used for biodegradable orthopedic metals in terms of toxicity, mechanical property, biocompatibility, and corrosion resistance [11]. The degradation products of iron $(\mathrm{Fe})$ mostly consist of Fe oxides and hydroxides, which are biocompatible with the human body [12]. Fe is found in four classes of proteins and enzymes [13]. Fe-containing proteins and enzymes exert a variety of functions including transporting, storing, and activating molecular oxygen [14]. In addition, Fe is an essential element for normal metabolism, growth, development, and maintenance of bones $[15,16]$. Recent studies show that proper dietary Fe intake may play a positive role in the prevention of osteoporosis in the female subgroup [16], while Fe deficiency adversely affects the cognitive development of children, increases maternal and infant mortality [17], and significantly influences bone mineral density, content, and fragility [18].

Thermal control ceramic coatings containing $\mathrm{Fe}, \mathrm{Co}, \mathrm{Ni}$, and $\mathrm{W}$ elements are black and they are prepared on titanium alloys due to their wide applications in aerospace, satellites, and many other fields [6]. Recently, Fe-containing MAO coatings with improved thermal and optical properties were fabricated by using $\mathrm{Fe}_{2}\left(\mathrm{SO}_{4}\right)_{3}$ on $\mathrm{AZ31} \mathrm{Mg}$ alloy [19] and $\mathrm{K}_{3}\left[\mathrm{Fe}\left(\mathrm{C}_{2} \mathrm{O}_{4}\right)_{3}\right]$ on MB2 $\mathrm{Mg}$ alloy [20]. However, the preparation of an Fe-containing coating on medical $\mathrm{Mg}$ alloy has not so far been reported. In this study, the highly water-soluble ferric sodium ethylenediaminetetraacetate (abbreviated as $\mathrm{NaFeY}, \mathrm{Y}=\left[\left(\mathrm{OOCCH}_{2}\right)_{2}-\mathrm{N}=\mathrm{CH}_{2} \mathrm{CH}_{2}=\mathrm{N}\left(\mathrm{CH}_{2} \mathrm{COO}\right)_{2}\right]$, which is a popular fortificant due to its high bioavailability that can significantly increase Fe and zinc availabilities in porridges [21], was used as the key electrolyte component and Fe-containing biomedical ceramic coatings were firstly fabricated by MAO on Mg alloy. The surface morphology, elemental valence state, and degradation resistance, as well as the in vitro cytocompatibility of MAO-treated samples were measured by scanning electron microscopy (SEM), X-ray photoelectron spectroscopy (XPS), potentiodynamic polarization measurements, and CCK-8 assay.

\section{Experimental}

Extruded WE43 Mg alloy was provided by Suzhou Chuan Mao Metal Materials Co., LTD (Suzhou, China) and its composition is listed in Table 1.

Table 1. Chemical composition of WE43 Mg alloy (in wt.\%).

\begin{tabular}{ccccccccc}
\hline Element & $\mathbf{Y}$ & $\mathbf{Z r}$ & $\mathbf{G d}$ & $\mathbf{N d}$ & $\mathbf{C u}$ & $\mathbf{N i}$ & $\mathbf{F e}$ & $\mathbf{M g}$ \\
\hline Standard value & $3.7-4.3$ & $0.4-1.0$ & $0-1.9$ & $2.0-2.5$ & $\leq 0.02$ & $\leq 0.005$ & $\leq 0.01$ & Balance \\
Tested value & 4.01 & 0.47 & 1.72 & 2.35 & 0.003 & 0.004 & 0.0003 & Balance \\
\hline
\end{tabular}

WE43 Mg alloy was firstly separately machined down to $45 \times 50 \times 8 \mathrm{~mm}^{3}$ for surface characteristics and $10 \times 10 \times 8 \mathrm{~mm}^{3}$ for electrochemical tests. Prior to MAO treatment, all machined samples were first ground using $\mathrm{SiC}$ waterproof abrasive paper from 80 to 3000 grits, then cleaned successively using tap and distilled water. A unipolar constant current mode was used in the study and the applied electrical parameters were a current density of $60 \mathrm{~mA} / \mathrm{cm}^{2}$, a duty cycle of $35 \%$, a pulse frequency of $2000 \mathrm{~Hz}$, and a treating time of 3 min using a homemade MAO5D power supply (Chengdu, China). A sample for MAO treatment and a stainless steel barrel containing the MAO solution were separately connected with the anode and the cathode. The used ammonium bifluoride $\left(\mathrm{NH}_{4} \mathrm{HF}_{2}\right)$, hexamethylenetetramine, phosphoric acid (PA), and NaFeY were of analytical reagent grade. Phytic acid (IP6) with a purity of $70 \%$ was purchased from Sinopharm Chemical Reagent Co., Ltd. (Shanghai, China). In a nearly neutral base solution containing $6 \mathrm{~g} / \mathrm{L} \mathrm{NH}_{4} \mathrm{HF}_{2}, 360 \mathrm{~g} / \mathrm{L}$ hexamethylenetetramine, $35 \mathrm{~g} / \mathrm{L} \mathrm{PA}$, and $8 \mathrm{~g} / \mathrm{L} \mathrm{IP6}$, samples of $0,6,12$, and $18 \mathrm{~g} / \mathrm{L} \mathrm{NaFeY}$ were separately added and the fabricated samples were named Fe-0 g/L, Fe-6 g/L, Fe-12 g/L, and Fe-18 g/L, respectively. 
After being sputtered with gold, the as-prepared MAO samples were measured by SIGMA scanning electron microscopy (SEM, Zeiss Sigma, Oberkochen, Germany) with an accelerating voltage of $20 \mathrm{kV}$ and coating compositions were analyzed by energy-dispersive spectrometry (EDS) attached to SEM. X-ray photoelectron spectroscopy (XPS, Kratos Analytical, Manchester, UK) was used to determine elemental valence states in MAO coatings. The binding energy values of each element were calibrated according to the adventitious $C 1$ s signal, which was set at $284.6 \mathrm{eV}$. The degradation resistance was evaluated using a conventional three-electrode electrochemical cell at $37 \pm 0.5^{\circ} \mathrm{C}$ in Hank's solution, which was composed of $8 \mathrm{~g} / \mathrm{L} \mathrm{NaCl}, 0.4 \mathrm{~g} / \mathrm{L} \mathrm{KCl}, 0.14 \mathrm{~g} / \mathrm{L} \mathrm{CaCl} 2,0.35 \mathrm{~g} / \mathrm{L} \mathrm{NaHCO}$, $1.0 \mathrm{~g} / \mathrm{L} \mathrm{C}_{6} \mathrm{H}_{12} \mathrm{O}_{6}, 0.2 \mathrm{~g} / \mathrm{L} \mathrm{MgSO}{ }_{4} \cdot 7 \mathrm{H}_{2} \mathrm{O}, 0.1 \mathrm{~g} / \mathrm{L} \mathrm{KH}_{2} \mathrm{PO}_{4}$, and $0.06 \mathrm{~g} / \mathrm{L} \mathrm{Na}{ }_{2} \mathrm{HPO}_{4} \cdot 7 \mathrm{H}_{2} \mathrm{O}$. At a scanning rate of $1 \mathrm{mV} / \mathrm{s}$ using a Gamry Reference 600 electrochemical workstation (Gamry Instruments, Lafayette, IL, USA), potentiodynamic polarization curves were measured from $-0.25 \mathrm{~V}$ to the open circuit potential $(\mathrm{OCP})$ toward a noble direction until film breakdown.

The cytotoxicity of the as-prepared samples was evaluated by the Cell Counting Kit-8 (CCK-8, Beyotime, Shanghai, China) assay. The mouse pre-osteoblast cells (MC3T3-E1) were seeded on the samples in 96-well culture plates at a density of $5 \times 10^{3}$ per well and incubated for $24 \mathrm{~h}$ to allow cell attachment. Then, the culture medium ( $\alpha$-MEM supplemented with $10 \%$ FBS) was replaced by extracts (the preparation method according to Reference [22]) supplemented with $10 \%$ FBS. After incubating for 1,3 , and 7 days, all samples were transferred to new wells. $\alpha$-MEM supplemented with $10 \%$ CCK- 8 was added into each well and cultured for another $2 \mathrm{~h}$. The absorbance was measured by using a microplate reader (Thermo Fisher Scientific, Waltham, MA, USA) at $450 \mathrm{~nm}$. The experiments were independently performed at least in triplicates.

\section{Results}

The variations in the working voltage with treatment time during the MAO process in the base solution with added 0, 6, 12, and $18 \mathrm{~g} / \mathrm{L} \mathrm{NaFeY}$ are shown in Figure 1.

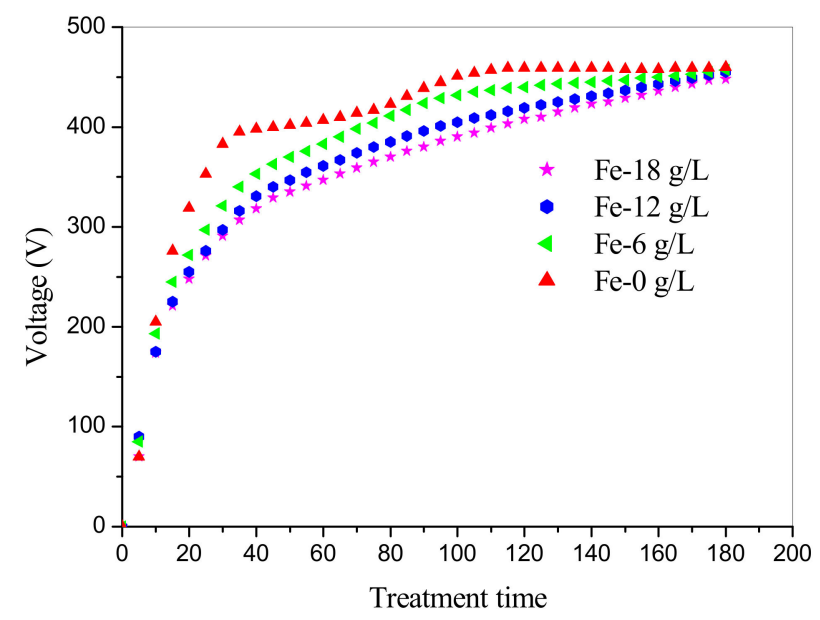

Figure 1. Variations in the working voltage with treatment time in the base solution with added 0,6 , 12 , and $18 \mathrm{~g} / \mathrm{L} \mathrm{NaFeY}$.

In the four solutions containing $0,6,12$, and $18 \mathrm{~g} / \mathrm{L} \mathrm{NaFeY}$, the working voltage increased very fast, separately reaching $319,272,255$, and $248 \mathrm{~V}$ during the first $20 \mathrm{~s}$. In the base solution without $\mathrm{NaFeY}$, the voltage went up to $398 \mathrm{~V}$ at $40 \mathrm{~s}$ and then the increasing rate slowed down. After $145 \mathrm{~s}$, the voltages began to fluctuate. When $\mathrm{Mg}$ samples were treated in the solutions containing 6, 12, and $18 \mathrm{~g} / \mathrm{L} \mathrm{NaFeY}$, the working voltages continually increased. The final voltages in solutions with 0,6 , 12, and $18 \mathrm{~g} / \mathrm{L} \mathrm{NaFeY}$ were 460, 457, 455, and $448 \mathrm{~V}$, respectively (Figure 1). Compared with the base solution without $\mathrm{NaFeY}$, the increased $\mathrm{NaFeY}$ concentrations decreased the working voltage but the final voltages did not exhibit evident differences. 
Figure 2 shows the surface morphologies and EDS spectra of MAO coatings developed on WE43 alloy. The coating on Fe-0 g/L was uneven and the maximum pore size was about $6.0 \mu \mathrm{m}$ (Figure 2(a1)). After the addition of NaFeY, it was clear that the pore size and the distance between two adjacent pores decreased (Figure 2(b1-d1)). EDS analysis showed that Fe-0 g/L contained 14.11 at.\% C, 51.33 at.\% O, 2.43 at.\% F, 18.40 at.\% Mg, and 13.72 at.\% P (Figure 2(a2)). The fabricated Fe-6 g/L, $\mathrm{Fe}-12 \mathrm{~g} / \mathrm{L}$, and Fe-18 g/L were composed of $0.78,1.53$, and 2.27 at.\% Fe, respectively (Figure 2(b2-d2)). This suggests that the enhanced Fe content in the coatings is closely pertinent to the increased $\mathrm{NaFeY}$ concentration.
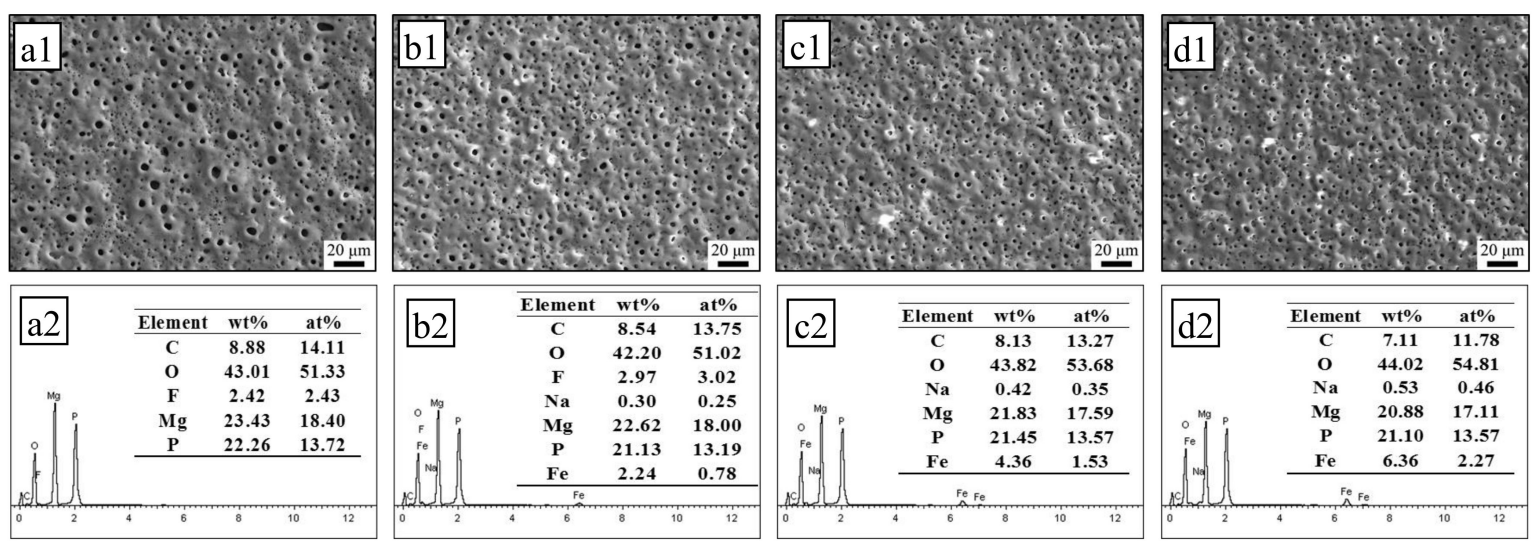

Figure 2. Surface morphologies (a1-d1) and chemical compositions (a2-d2) of micro-arc oxidation (MAO) coatings fabricated in the base solution with different $\mathrm{NaFeY}$ concentrations: (a1,a2) Fe-0 g/L; (b1,b2) Fe-6 g/L; (c1,c2) Fe-12 g/L; (d1,d2) Fe-18 g/L.

The high-resolution XPS spectra of $\mathrm{O}, \mathrm{P}, \mathrm{Mg}$, and Fe elements in Fe-12 g/L are shown in Figure 3. The $\mathrm{O} 1 \mathrm{~s}$ spectrum could be divided into three peaks at the binding energy of 530.0, 531.6, and $532.2 \mathrm{eV}$, corresponding to $\mathrm{Fe}_{2} \mathrm{O}_{3}$ [14], $\mathrm{PO}_{4}{ }^{3-}$ [23], and $\mathrm{OH}^{-}$[24], respectively. The binding energy of $\mathrm{Mg}$ 1s was centered at 1304.0 and $1304.9 \mathrm{eV}$ (Figure $3 \mathrm{~b}$ ), indicating that the magnesium element in MAO coatings existed as $\mathrm{MgO}$ and magnesium phosphate [25], respectively. The P 2p spectrum showed two peaks at 133.4 and $134.1 \mathrm{eV}$ (Figure 3c), assigned to $\mathrm{PO}_{4}{ }^{3-}$ and $\mathrm{HPO}_{4}{ }^{2-}$ [23], respectively. Figure $2 \mathrm{~d}$ shows that the Fe $2 p$ peaks with a binding energy of $2 p_{3 / 2}$ at $711.1 \mathrm{eV}$ and $2 \mathrm{p}_{1 / 2}$ at $724.4 \mathrm{eV}$ correspond to $\mathrm{Fe}_{2} \mathrm{O}_{3}[26]$.

The potentiodynamic polarization curves of the MAO-treated samples are shown in Figure 4. The relevant electrochemical parameters derived from the potentiodynamic polarization curves are summarized in Table 2 . The achieved corrosion current densities $\left(\mathrm{i}_{\text {corr }} \mathrm{s}\right)$ of the substrate, $\mathrm{Fe}-0 \mathrm{~g} / \mathrm{L}, \mathrm{Fe}-6 \mathrm{~g} / \mathrm{L}$, Fe-12 g/L, and Fe-18 g/L were $1.13 \times 10^{-5}, 6.26 \times 10^{-7}, 8.55 \times 10^{-7}, 9.66 \times 10^{-7}$, and $1.24 \times 10^{-6} \mathrm{~A} / \mathrm{cm}^{2}$, respectively, indicating that compared with the substrate, MAO-treated samples significantly improved the degradation resistance. However, with the increase in the $\mathrm{NaFeY}$ concentration, the degradation resistance of MAO samples became worse, showing that $\mathrm{NaFeY}$ was harmful to the degradation resistance of anodic coatings. 


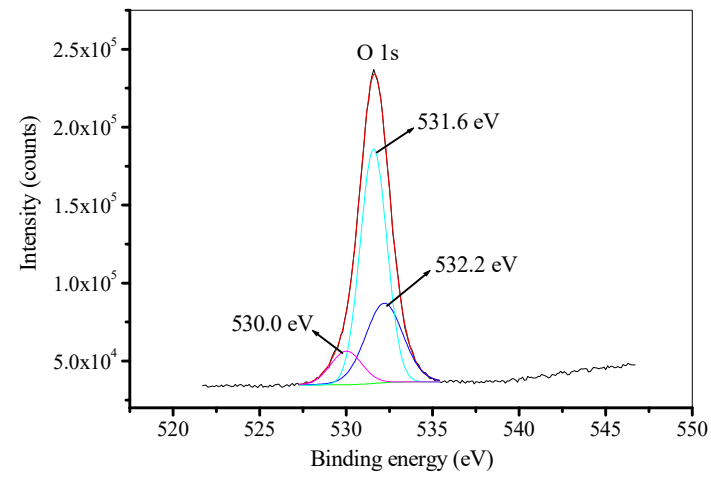

(a)

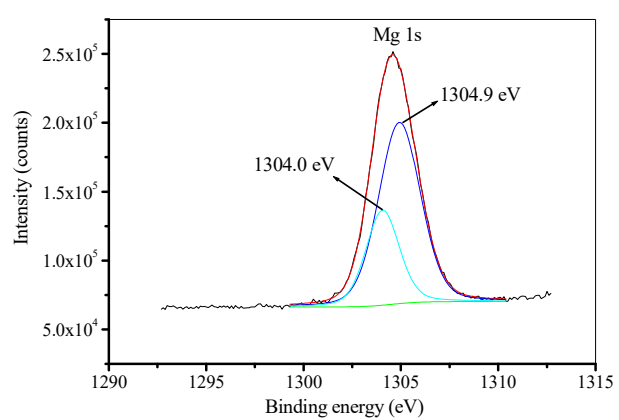

(c)

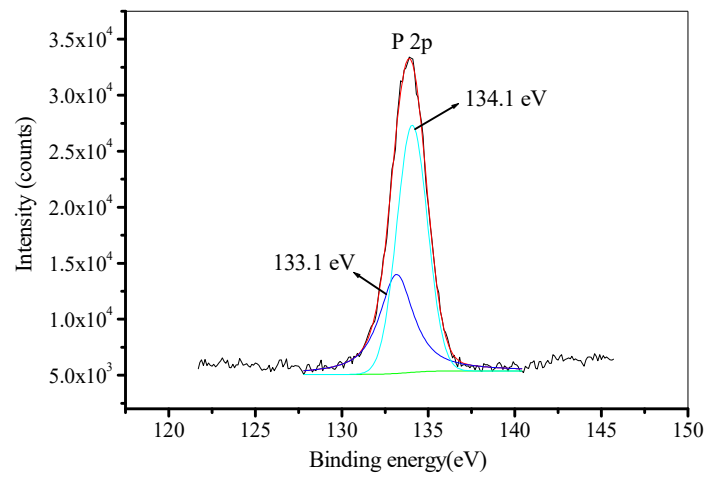

(b)

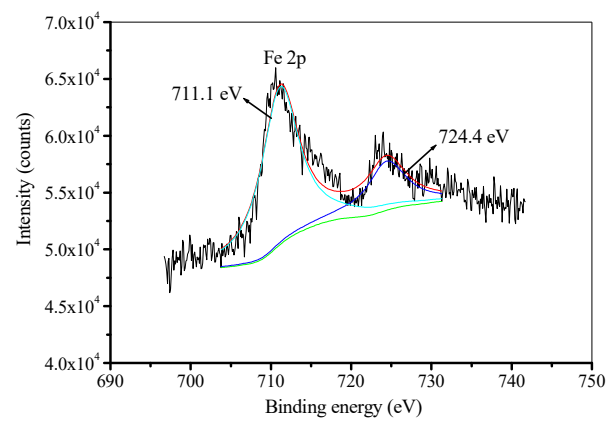

(d)

Figure 3. High-resolution XPS spectra of Fe-12 g/L: (a) O 1s; (b) P 2p; (c) Mg 1s; (d) Fe 2p.

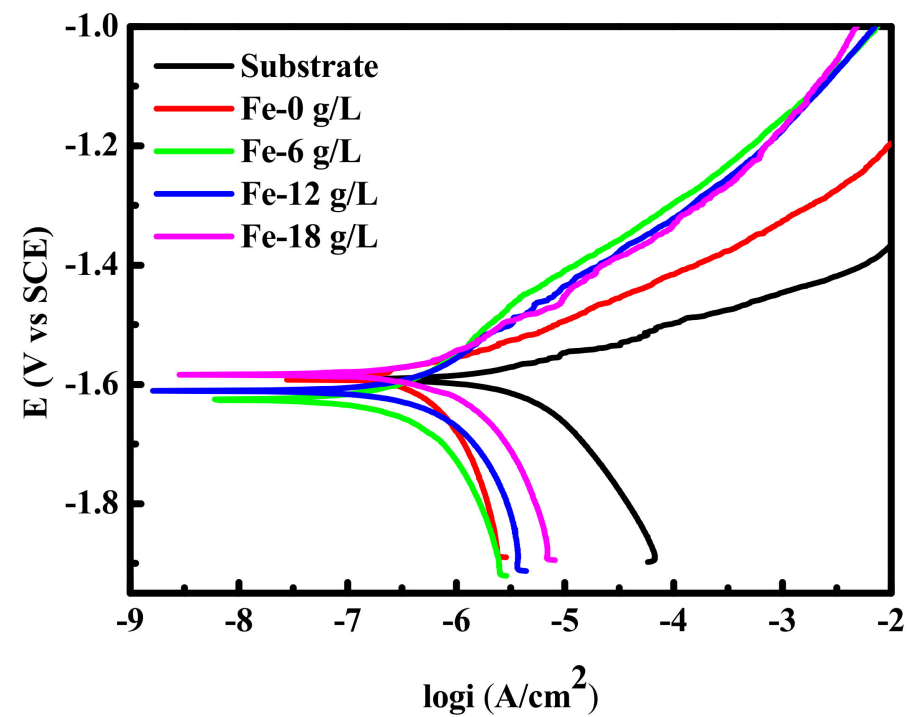

Figure 4. Potentiodynamic polarization curves of MAO samples fabricated in solutions containing different $\mathrm{NaFeY}$ concentrations. 
Table 2. The electrochemical parameters of MAO samples fabricated in solutions containing different $\mathrm{NaFeY}$ concentrations.

\begin{tabular}{ccccc}
\hline Samples & $\begin{array}{c}\boldsymbol{\beta a} \\
(\mathbf{m V} / \mathbf{d e c})\end{array}$ & $\begin{array}{c}\boldsymbol{\beta c} \\
(\mathbf{m V} / \mathbf{d e c})\end{array}$ & $\begin{array}{c}\mathbf{i}_{\text {corr }} \\
\left(\mathbf{A} / \mathbf{c m}^{\mathbf{2}}\right)\end{array}$ & $\begin{array}{c}\mathbf{E}_{\text {corr }} \\
(\mathbf{V} \text { vs. SCE) }\end{array}$ \\
\hline Substrate & 313.21 & 316.26 & $1.13 \times 10^{-5}$ & -1.6045 \\
$\mathrm{Fe}-0 \mathrm{~g} / \mathrm{L}$ & 89.571 & 383.30 & $6.26 \times 10^{-7}$ & -1.5898 \\
$\mathrm{Fe}-6 \mathrm{~g} / \mathrm{L}$ & 270.08 & 497.36 & $8.55 \times 10^{-7}$ & -1.6260 \\
$\mathrm{Fe}-12 \mathrm{~g} / \mathrm{L}$ & 220.14 & 376.65 & $9.66 \times 10^{-7}$ & -1.6129 \\
$\mathrm{Fe}-18 \mathrm{~g} / \mathrm{L}$ & 141.88 & 311.71 & $1.24 \times 10^{-6}$ & -1.5839 \\
\hline
\end{tabular}

The in vitro cytocompatibility of the MAO-treated samples was assessed by CCK-8 assay and the results are shown in Figure 5. Compared with the substrate (Figure 5b), polygonal MC3T3-E1 cells evidently spread on MAO-treated samples with more filose pseudopodium (Figure 5c-f), suggesting that the MAO-treated samples exhibited better initial cell attachment than the substrate. After being cultivated with cells in the extracts for 1, 3, and 7 days, each MAO-treated sample fabricated in four solutions showed significantly higher cell viability than the substrate (Figure 5a). Furthermore, no significant difference could be observed between the MAO-treated samples and the control, suggesting that MAO-treated samples achieved good in vitro cytocompatibility.
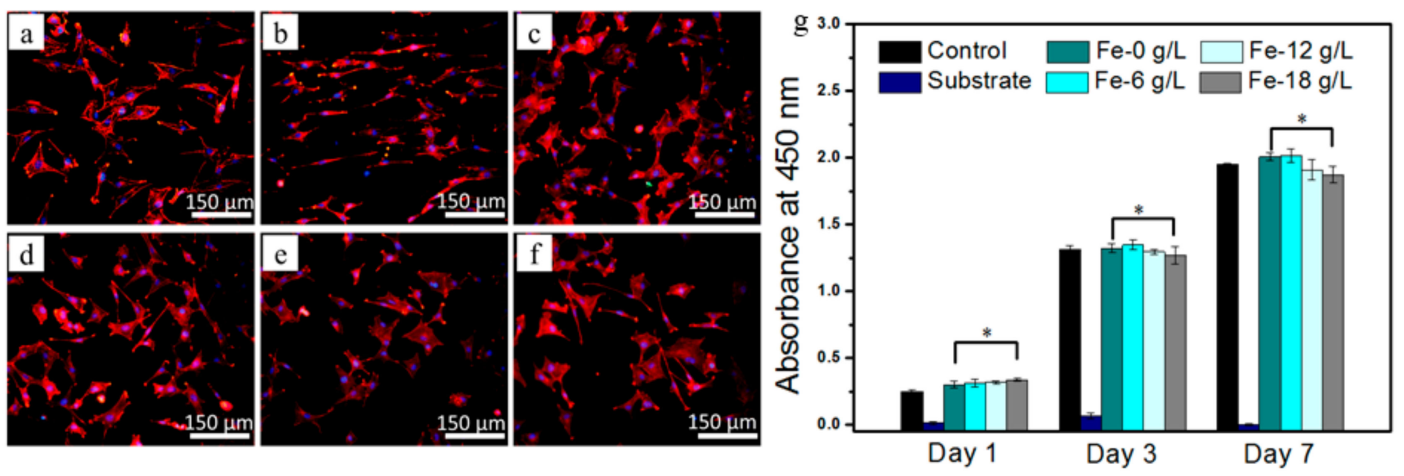

Figure 5. Fluorescent images of MC3T3-E1 cells after culturing for $5 \mathrm{~h}$ on (a) control, (b) substrate, (c) Fe-0 g/L, (d) Fe-6 g/L, (e) Fe-12 g/L, and (f) Fe-18 g/L, and (g) absorbance values of the MC3T3-E1 pre-osteoblasts cultured for 1, 3, and 7 days on control, substrate, and MAO-treated samples with different Fe amounts. ${ }^{*} p<0.05$ compared to substrate.

\section{Discussion}

\subsection{Formation of Fe-Containing Ceramic Coating}

In order to fabricate an Fe-containing MAO coating on $\mathrm{Mg}$ alloy, the selection of the Fe-containing electrolyte is very important. $\mathrm{NaFeY}$, one kind of ferric salt with both excellent solubility in water and chelating ability, was chosen in the study as the Fe-containing electrolyte. In addition, PA and IP6 were used as phosphorus-containing electrolytes. According to Figure 2, the fabricated Fe-0 g/L, Fe-6 g/L, Fe-12 g/L, and Fe-18 g/L were composed of 13.72, 13.19, 13.57, and 13.57 at.\% P, respectively (Figure 2(b1-d2)), indicating that both PA and IP6 took part in the coating formation [27,28]. IP6 exhibits a strong chelating ability with positively charged multivalent ions due to its chemical structure, namely six phosphates being connected to one inositol ring [29].Therefore, in MAO solutions, IP6 competes with $\mathrm{FeY}^{4-}$ to combine with $\mathrm{Fe}^{3+}$ ions into phytic acid complexes.

According to Figure 3, $\mathrm{Mg}_{3}\left(\mathrm{PO}_{4}\right)_{2}$ and $\mathrm{MgHPO}_{4}$ were developed in $\mathrm{MAO}$ coatings. During MAO, $\mathrm{FeY}^{-}, \mathrm{PO}_{4}{ }^{3-}$, and phytic acid complexes migrate toward the anode under the electric field and join in the coating formation according to the following reactions [10,30]:

$$
\mathrm{Mg}-2 \mathrm{e}^{-}=\mathrm{Mg}^{2+}
$$




$$
\begin{gathered}
3 \mathrm{Mg}^{2+}+2 \mathrm{PO}_{4}{ }^{3-}=\mathrm{Mg}_{3}\left(\mathrm{PO}_{4}\right)_{2} \\
\mathrm{Mg}^{2+}+\mathrm{HPO}_{4}{ }^{2-}=\mathrm{MgHPO}_{4} \\
\mathrm{FeY}^{-} \leftrightarrows \mathrm{Fe}^{3+}+\mathrm{Y}^{4-} \\
\mathrm{Fe}^{3+}+3 \mathrm{OH}^{-}=\mathrm{Fe}(\mathrm{OH})_{3} \\
2 \mathrm{Fe}(\mathrm{OH})_{3}=\mathrm{Fe}_{2} \mathrm{O}_{3}+3 \mathrm{H}_{2} \mathrm{O}
\end{gathered}
$$

\subsection{Degradation Resistance of Fe-Containing Ceramic Coating}

According to our previous results, it is difficult to fabricate a uniform MAO coating with a high Fe amount on $\mathrm{Mg}$ alloy in an alkaline solution containing NaFeY. Only in solutions containing high concentrations of fluorides and strong alkalines such as $\mathrm{NaOH}$ or $\mathrm{KOH}$, can an $\mathrm{MAO}$ coating with poor degradation resistance and a low amount of the Fe element be successfully developed on $\mathrm{Mg}$ alloy. Fluorides are helpful for coating formation on $\mathrm{Mg}$ alloy [30,31], but they are toxic to the environment. In this study, besides a small amount of $\mathrm{NH}_{4} \mathrm{HF}_{2}(6 \mathrm{~g} / \mathrm{L}), 360 \mathrm{~g} / \mathrm{L}$ hexamethylenetetramine, which has been used as the passive agent of Mg alloy [32], was selected to develop an MAO coating in neutral solutions.

After 6,12 , and $18 \mathrm{~g} / \mathrm{L} \mathrm{NaFeY}$ samples were separately added into the base solution, the $\mathrm{i}_{\text {corr }}$ of the fabricated MAO samples continually increased, suggesting that $\mathrm{FeY}^{-}$was harmful to the degradation resistance of MAO-treated samples. According to Figure 1, NaFeY concentrations did not significantly influence the working voltage, suggesting that $\mathrm{NaFeY}$ may influence the coating degradation resistance by surface characteristics. Our recent results show that with the increase in $\mathrm{Na}_{2} \mathrm{CaY}$ concentrations, the corrosion resistance of MAO samples becomes worse, attributed to the continually decreased coating thickness [28]. As an organic additive agent with a strong chelating ability, EDTA can improve the uniformity of MAO coatings but decrease the coating thickness [33]. Combined with the previous reports $[28,33]$ and our present results, it can be concluded that $Y^{4-}$ decreases the degradation resistance of MAO-treated Mg alloy. However, the mechanism is not clear and future work will be conducted to clarify it.

\subsection{In Vitro Cytocompatibility of Fe-Containing Ceramic Coating}

The cytocompatibility of an anodic coating is determined by several factors, for example, degradation resistance and chemical composition. Fluorine $(F)$ is an essential trace element and the proper amount is beneficial to human health. However, when the $\mathrm{F}$ amount in an anodic coating is too high ( $\geq 19.00$ at.\%), the fabricated sample exhibits high toxicity [28]. In this study, $6 \mathrm{~g} / \mathrm{L} \mathrm{NH} \mathrm{NH}_{2} \mathrm{HF}_{2}$ was added as one kind of passive agent, and the F contents in anodic coatings were lower than 3.02 at. $\%$ and revealed good cytocompatibility. In addition to the F element, the cytocompatibility of anodic coatings is closely related to Fe presence. The results show that proper Fe ions are beneficial for cell growth [14]. However, in the study, with the increase in Fe contents in MAO coatings, the cytocompatibility did not significantly improve (Figure 5), which may be attributed to the synergistic effect of the coating composition and degradation resistance. The results show that the degradation resistance is positively related to the coating biocompatibility [11]. Once the NaFeY concentration is increased from 6 to 12 and $18 \mathrm{~g} / \mathrm{L}, \mathrm{Fe}$ amounts in anodic coatings continually increase, enhancing the cytocompatibility. However, the increased $\mathrm{NaFeY}$ concentration diminished the coating degradation resistance, which resulted in a slight decrease in cytocompatibility. Consequently, Fe-6 g/L with a lower Fe content but higher degradation resistance resulted in better cytocompatibility, whereas Fe-12 g/L or Fe-18 g/L with a higher Fe content exhibited a slightly lower cytocompatibility.

\section{Conclusions}

As an essential trace element for life, Fe plays vital functions to maintain human health. It is meaningful to prepare Fe-containing coatings on $\mathrm{Mg}$ alloy with improved degradation resistance and in vitro cytocompatibility. In a nearly neutral base solution with $6 \mathrm{~g} / \mathrm{L} \mathrm{NH}_{4} \mathrm{HF}_{2}, 360 \mathrm{~g} / \mathrm{L}$ 
hexamethylenetetramine, $35 \mathrm{~g} / \mathrm{L}$ PA, and $8 \mathrm{~g} / \mathrm{L} \mathrm{IP6}$, Fe-containing coatings were successfully fabricated on WE43 Mg alloy by MAO treatment. The effects of NaFeY concentrations on the MAO process, surface morphology, chemical composition, elemental valence state, degradation, and in vitro cytocompatibility were investigated. Some conclusions are drawn as follows:

(1) In the base solution with $0,6,12$, and $18 \mathrm{~g} / \mathrm{L} \mathrm{NaFeY}$, the final voltages were $460,457,455$, and $448 \mathrm{~V}$, respectively. The developed MAO coatings in solutions with 6,12 , and $18 \mathrm{~g} / \mathrm{L} \mathrm{NaFeY}$ contained $0.78,1.53$, and 2.27 at.\% Fe, respectively. Fe is mainly present as $\mathrm{Fe}_{2} \mathrm{O}_{3}$ in MAO coatings.

(2) Compared with the bare sample, the developed Fe-containing MAO coatings significantly improve the degradation resistance and in vitro cytocompatibility. The increased NaFeY concentration is favorable to the enhancement of the Fe content but harmful to the degradation resistance of MAO coatings.

(3) The cytocompatibility of MAO-treated samples is synergistically determined by the degradation resistance and chemical compositions. MAO-treated samples with low $\mathrm{Fe}$ amounts $(\mathrm{Fe}-6 \mathrm{~g} / \mathrm{L})$ achieved better cytocompatibility than those with higher Fe amounts (Fe-12 g/L or Fe-18 g/L).

Author Contributions: Conceptualization, R.Z. (Rongfa Zhang) and Y.Z. (Ying Zhao); software, G.L.; formal analysis, X.S. and Y.Z. (Yuanyuan Zhu); investigation, Z.Z. and Z.C.; writing-original draft preparation, Z.Z.; writing-review and editing, S.Z. and R.Z. (Rongfang Zhao). All authors have read and agreed to the published version of the manuscript.

Funding: The study was financially supported by National Natural Science Foundation of China (51661010, 81572113, 51861007), National College Students Innovative training program (202011318010) and Scientific Research Fund of Jiangxi Provincial Education Department (GJJ180617).

Acknowledgments: We appreciate the valuable comments provided by other members of our laboratories.

Conflicts of Interest: The authors declare no conflict of interest.

\section{References}

1. Narayanan, T.S.; Park, I.S.; Lee, M.H. Strategies to improve the corrosion resistance of microarc oxidation (MAO) coated magnesium alloys for degradable implants: Prospects and challenges. Prog. Mater. Sci. 2014, $60,1-71$.

2. Yin, Z.Z.; Qi, W.C.; Zeng, R.C.; Chen, X.B.; Gu, C.D.; Guan, S.K.; Zheng, Y.F. Advances in coatings on biodegradable magnesium alloys. J. Magn. Alloy. 2020, 8, 42-65.

3. Wang, Y.M.; Wang, F.H.; Xu, M.J.; Zhao, B.; Guo, L.X.; Ouyang, J.H. Microstructure and corrosion behavior of coated AZ91 alloy by microarc oxidation for biomedical application. Appl. Surf. Sci. 2009, 255, 9124-9131.

4. Simchen, F.; Sieber, M.; Kopp, A.; Lampke, T. Introduction to Plasma Electrolytic Oxidation-An Overview of the Process and Applications. Coatings 2020, 10, 628. [CrossRef]

5. Yao, Z.P.; Jia, F.Z.; Tian, S.J.; Li, C.X.; Jiang, Z.H.; Bai, X.F. Microporous Ni-Doped $\mathrm{TiO}_{2}$ film Photocatalyst by Plasma Electrolytic Oxidation. ACS Appl. Mater. Interfaces 2010, 9, 2617-2622.

6. Yao, Z.P.; Hu, B.; Shen, Q.X.; Niu, A.X.; Jiang, Z.H.; Su, P.B.; Ju, P.F. Preparation of black high absorbance and high emissivity thermal control coating on Ti alloy by plasma electrolytic oxidation. Surf. Coat. Technol. 2014, 253, 166-170. [CrossRef]

7. Shi, Z.M.; Song, G.L.; Atrens, A. Influence of the $\beta$ phase on the Corrosion Performance of Anodised Coatings on Magnesium-aluminium Alloys. Corros. Sci. 2006, 47, 2760-2777, reprinted in Surf. Coat. Technol. 2006, $201,492$.

8. Arrabal, R.; Matykina, E.; Viejo, F.; Skeldon, P.; Thompson, G. Corrosion resistance of WE43 and AZ91D magnesium alloys with phosphate PEO coatings. Corros. Sci. 2008, 50, 1744-1752. [CrossRef]

9. Toulabifard, A.; Rahmati, M.; Raeissi, K.; Hakimizad, A.; Santamaria, M. The Effect of Electrolytic Solution Composition on the Structure, Corrosion, and Wear Resistance of PEO Coatings on AZ31 Magnesium Alloy. Coatings 2020, 10, 937. [CrossRef]

10. Zhang, R.; Shan, D.; Chen, R.; Han, E. Effects of electric parameters on properties of anodic coatings formed on magnesium alloys. Mater. Chem. Phys. 2008, 107, 356-363. [CrossRef] 
11. Adhilakshmi, A.; Ravichandran, K.; Narayanan, T.S. Protecting electrochemical degradation of pure iron using zinc phosphate coating for biodegradable implant applications. New J. Chem. 2018, 42, 18458-18468. [CrossRef]

12. Yang, Y.; Zhou, J.; Detsch, R.; Taccardi, N.; Heise, S.; Virtanen, S.; Boccaccini, A.R. Biodegradable nanostructures: Degradation process and biocompatibility of iron oxide nanostructured arrays. Mater. Sci. Eng. C 2018, 85, 203-213. [CrossRef]

13. Fraga, C.G. Relevance, essentiality and toxicity of trace elements in human health. Mol. Asp. Med. 2005, 26, 235-244. [CrossRef]

14. Li, M.; Xu, X.C.; Jia, Z.J.; Shi, Y.Y.; Cheng, Y.; Zheng, Y.F. Rapamycin-loaded nanoporous $\alpha-\mathrm{Fe}_{2} \mathrm{O}_{3}$ as an endothelial favorable and thromboresistant coating for biodegradable drug-eluting Fe stent applications. J. Mater. Chem. B 2017, 6, 1182-1194.

15. Yang, J.; Zhang, J.; Ding, C.; Dong, D.; Shang, P. Regulation of Osteoblast Differentiation and Iron Content in MC3T3-E1 Cells by Static Magnetic Field with Different Intensities. Biol. Trace Element Res. 2018, 184, 214-225. [CrossRef]

16. Xiong, Y.; Wei, J.; Zeng, C.; Yang, T.; Li, H.; Deng, Z.; Zhang, Y.; Ding, X.; Yang, Y.; Lei, G. Association between dietary iron intake and bone mineral density: A cross-sectional study in Chinese population. Nutr. Diet. 2016, 5, 433-440.

17. Jaramillo, A.; Briones, L.; Andrews, M.; Arredondo, M.; Olivares, M.; Brito, A.; Pizarro, F. Effect of phytic acid, tannic acid and pectin on fasting iron bioavailability both in the presence and absence of calcium. J. Trace Elements Med. Biol. 2015, 30, 112-117. [CrossRef]

18. Yin, Y.; Li, Y.; Li, Q.; Jia, N.; Liu, A.; Tan, Z.; Wu, Q.; Fan, Z.; Li, T.; Wang, L. Evaluation of the Relationship Between Height and Zinc, Copper, Iron, Calcium, and Magnesium Levels in Healthy Young Children in Beijing, China. Biol. Trace Element Res. 2017, 176, 244-250.

19. Lu, S.; Qin, W.; Wu, X.; Wang, X.; Zhao, G. Effect of $\mathrm{Fe}^{3+}$ ions on the thermal and optical properties of the ceramic coating grown in-situ on AZ31 Mg Alloy. Mater. Chem. Phys. 2012, 135, 58-62. [CrossRef]

20. Song, Z.K.; Wang, X.D.; Cai, Y.R.; Song, Q.Q. Effect of adding $\mathrm{K}_{3}\left[\mathrm{Fe}\left(\mathrm{C}_{2} \mathrm{O}_{4}\right)_{3}\right]$ on the characteristics of the magnesium alloy micro-arc oxidation coating. J. Dispers. Sci. Technol. 2019, 41, 1319-1325. [CrossRef]

21. Kruger, J. Replacing electrolytic iron in a fortification-mix with NaFeEDTA increases both iron and zinc availabilities in traditional African maize porridges. Food Chem. 2016, 205, 9-13. [CrossRef]

22. Wang, Y.; Lou, J.; Zeng, L.; Xiang, J.; Zhang, S.; Wang, J.; Xiong, F.; Li, C.; Zhao, Y.; Zhang, R. Osteogenic potential of a novel microarc oxidized coating formed on Ti6Al4V alloys. Appl. Surf. Sci. 2017, 412, 29-36. [CrossRef]

23. Zhu, X.; Chen, J.; Scheideler, L.; Reichl, R.; Geis-Gerstorfer, J. Effects of topography and composition of titanium surface oxides on osteoblast responses. Biomater. 2004, 25, 4087-4103. [CrossRef]

24. Frateur, I.; Carnot, A.; Zanna, S.; Marcus, P. Role of pH and calcium ions in the adsorption of an alkyl $\mathrm{N}$-aminodimethylphonate on steel: An XPS study. Appl. Surf. Sci. 2006, 252, 2757-2769.

25. Li, G.Q.; Wang, Y.P.; Zhang, S.F.; Zhao, R.F.; Zhang, R.F.; Li, X.Y.; Chen, C.M. Investigation on entrance mechanism of calcium and magnesium into micro-arc oxidation coatings developed on Ti-6Al-4V alloys. Surf. Coat. Technol. 2019, 378, 124951.

26. Yamashita, T.; Hayes, P. Analysis of XPS spectra of $\mathrm{Fe}^{2+}$ and $\mathrm{Fe}^{3+}$ ions in oxide materials. Appl. Surf. Sci. 2008, 254, 2441-2449. [CrossRef]

27. Zeng, R.C.; Cui, L.Y.; Jiang, K.; Liu, R.; Zhao, B.D.; Zheng, Y.F. In vitro corrosion and cytocompatibility of a micro-arc oxidation coating and poly(L-lactic acid composite coating on Mg-1Li-1Ca alloy for orghopedic implants. ACS Appl. Mater. Inter. 2016, 8, 10014-10028.

28. Shi, X.; Wang, Y.; Li, H.; Zhang, S.; Zhao, R.; Li, G.; Zhang, R.; Sheng, Y.; Cao, S.; Zhao, Y.; et al. Corrosion resistance and biocompatibility of calcium-containing coatings developed in near-neutral solutions containing phytic acid and phosphoric acid on AZ31B alloy. J. Alloy. Compd. 2020, 823, 153721. [CrossRef]

29. Kumar, V.; Sinha, A.K.; Makkar, H.P.; Becker, K. Dietary roles of phytate and phytase in human nutrition: A review. Food Chem. 2010, 120, 945-959. [CrossRef]

30. Simchen, F.; Sieber, M.; Mehner, T.; Lampke, T. Characterisation Method of the Passivation Mechanisms during the pre-discharge Stage of Plasma Electrolytic Oxidation indicating the Mode of Action of Fluorides in PEO of Magnesium. Coatings 2020, 10, 965. [CrossRef] 
31. Zhu, Y.Y.; Chang, W.H.; Zhang, S.F.; Song, Y.W.; Huang, H.D.; Zhao, R.F.; Li, G.Q.; Zhang, R.F.; Zhang, Y.J. Investigation on Corrosion Resistance and Formation Mechanism of a P-F-Zr Contained Micro-Arc Oxidation Coating on AZ31B Magnesium Alloy Using an Orthogonal Method. Coatings 2019, 9, 197. [CrossRef]

32. Echeverry-Rendon, M.; Duque, V.; Quintero, D.; Robledo, S.M.; Harmsen, M.C.; Echeverria, F. Improved corrosion resistance of commercially pure magnesium after its modification by plasma electrolytic oxidation with organic additives. J. Biomater. Appl. 2018, 5, 725-740.

33. Shi, L.L.; Xu, Y.J.; Li, K.; Yao, Z.P.; Wu, S.Q. Effect of additives on structure and corrosion resistance of ceramic coatings on Mg-Li alloy by micro-arc oxidation. Curr. Appl. Phys. 2010, 10, 719-723. [CrossRef]

Publisher's Note: MDPI stays neutral with regard to jurisdictional claims in published maps and institutional affiliations.

(C) 2020 by the authors. Licensee MDPI, Basel, Switzerland. This article is an open access article distributed under the terms and conditions of the Creative Commons Attribution (CC BY) license (http://creativecommons.org/licenses/by/4.0/). 